\title{
A pedagogia militar e a formação em direitos humanos nas missões de paz: uma interdisciplinaridade necessária
}

\section{Military pedagogy and training in human rights in peace missions: a necessary interdisciplinary}

La formación pedagogia militar en derechos humanos en misiones de paz: una interdisciplinaridad necesario

Paulo Sérgio Xavier ${ }^{1}$ Jefferson Gomes Nogueira² Lucrécia Stringhetta Mello

${ }^{1}$ Mestre em Educação pelo Programa de Pós-Graduação em Educação da Universidade Federal de Mato Grosso do Sul (UFMS). Graduado em Direito pela Faculdade Novo Milênio de Vila Velha, ES. E-mail: sgtxavier1993@yahoo.com.br

${ }^{2}$ Mestre em Educação pela Universidade Federal de Mato Grosso do Sul (UFMS); Mestre em História pela Universidade Federal do Espírito Santo (UFES). Professor Substituto da Universidade Federal de Juiz de Fora (UFJF). E-mail: prof_jefferson@yahoo.com.br

${ }^{3}$ Doutora em Educação pela Pontifícia Universidade Católica de São Paulo (PUC-SP). Professora do Programa de Pós-Graduação em Educação da Universidade Federal de Mato Grosso do Sul (UFMS). E-mail: lucrecia.mello@uol.com.br 
Resumo: As pesquisas realizadas nos programas de Pós-Graduação no Brasil, cujo foco é a Instituição Escolar, em sua quase totalidade, privilegiam as instituições civis de ensino, em detrimento da Educação Militar. A categoria militar sempre esteve presente e intervindo nos momentos de graves crises políticas e institucionais. O relatório final da Comissão Nacional da Verdade (2014) recomenda uma reformulação dos concursos de ingresso e dos processos de avaliação contínua nas Forças Armadas e na área de segurança pública, de modo a valorizar o conhecimento sobre os preceitos inerentes à democracia e aos direitos humanos. A interdisciplinaridade possibilitou-nos adotar a polissemia conceitual ao invés de generalizações, destacando da análise bibliográfica resultados válidos e representativos desse fenômeno. Weber (1982), Gusdorf (1961), Althusser (1985), Bobbio (1992) nos fornecem respaldo teórico para concluir que a categoria militar carece de uma preparação interdisciplinar que conjugue a Formação Militar e a Educação em Direitos Humanos.

Palavras-chave: educação militar; direitos humanos; interdisciplinaridade.

Abstract: The research carried out in the Graduate Programs in Brazil, whose focus is the School Institution, almost all privilege the civil institutions of education, to the detriment of Military Education. The military category has always been present and intervening in times of serious political and institutional crises. The final report of the National Truth Commission (2014) recommends a reformulation of entrance examinations and continuous evaluation processes in the Armed Forces and in the area of public security, in order to enhance knowledge about the precepts inherent to democracy and human rights. The interdisciplinarity allowed us to adopt conceptual polysemy rather than generalizations, highlighting from the bibliographic analysis valid and representative results of this phenomenon. Weber (1982), Gusdorf (1961), Althusser (1985), Bobbio (1992) provide theoretical support to conclude that the military category lacks interdisciplinary preparation that combines Military Education and Human Rights Education.

Key words: military education; human rights; interdisciplinarity.

Resumen: La investigación en los programas de posgrado en Brasil, que se centra en la institución escolar en casi todas favorecer a las instituciones civiles de la educación, a expensas de Educación Militar. categoría militar ha estado siempre presente e intervenir en situaciones de grave crisis política e institucional. El informe final de la Comisión Nacional de la Verdad (2014) recomienda un rediseño de las pruebas de acceso y procesos de evaluación continua en la seguridad militar y pública con el fin de mejorar el conocimiento de los principios inherentes a la democracia y los derechos humanos. El enfoque interdisciplinar nos permitió adoptar la polisemia conceptual en lugar de generalizaciones, destacando el análisis de la literatura válido y representativo de este fenómeno resulta. Weber (1982), Gusdorf (1961), Althusser (1985), Bobbio (1992) para proporcionar el apoyo teórico para la conclusión de que la categoría militar carece de una preparación interdisciplinaria que combina la formación militar y la Educación en Derechos Humanos.

Palabras clave: la educacion militar; derechos humanos; interdisciplinariedad. 
A pedagogia militar e a formação em direitos humanos nas missões de paz: uma interdisciplinaridade necessária

\section{INTRODUÇÃO}

Assim que nascemos, somos inseridos em uma sociedade com regras preestabelecidas, em que a conduta e, muitas vezes, as ideias e os pensamentos são preconcebidos na mentalidade coletiva. A maneira pela qual estamos habituados a agir foi esboçada por Montesquieu ${ }^{1}$. Segundo ele, faz-se necessária uma organização, as sociedades não estão organizadas a esmo, e essa esfera do universo é governada por leis. Nesse sentido, educar é, antes de tudo mais, organizar a experiência dos indivíduos na vida cotidiana, desenvolver-lhes a personalidade e garantir-Ihes a sobrevivência. As ações empreendidas com a finalidade de educar estão diretamente relacionadas às normas sociais vigentes e aos valores compartilhados pelos indivíduos, no contexto de determinada sociedade, de determinada cultura e de determinado contexto histórico (RODRIGUES, 2008).

No senso comum, a noção de direitos humanos está frequentemente associada àquelas pessoas que "defendem bandidos", entretanto essa percepção é equivocada, superficial e falaciosa. Antes de conceituarmos direitos humanos ${ }^{2}$, devemos partir do primordial, do básico. O direito humano fundamental e basilar é o direito à vida, em que, para realizar-se, o indivíduo necessita de um mínimo de alimentos e água potável que garantam sua sobrevivência. Ainda nessa linha "sucessória" de direitos humanos, podemos dizer que o "segundo" direito humano essencialmente necessário é o direito à educação, haja vista que a educação é um direito humano e social universal, que precisa ser garantido a todas as pessoas sem distinção de cor, sexo, gênero ou condição social (Organização das Nações Unidas para a Educação, a Ciência e a Cultura [UNESCO]). Nesse sentido entendemos

\footnotetext{
${ }^{1}$ Charles-Louis de Secondat, barão de La Brède e de Montesquieu, conhecido como Montesquieu, foi um político, filósofo e escritor francês (1689-1755).

${ }^{2} \mathrm{O}$ que vai ser feito num segundo momento deste artigo.
} 
ser o direito à educação uma garantia de acesso aos demais direitos, sejam eles sociais, políticos, econômicos ou culturais.

No que tange à educação militar, temos que as pesquisas realizadas nos programas de Pós-Graduação no Brasil, cujo foco é a Instituição Escolar, em sua quase totalidade privilegiam as instituições civis de ensino, ficando o estudo e pesquisa de temáticas sobre o pensamento, a história e o ethos militar ${ }^{3}$ à margem das pesquisas acadêmicas. Como na história do Brasil a categoria militar sempre esteve presente e intervindo nos momentos de graves crises institucionais, dá-se a relevância de se estudar tanto o pensamento quanto o ensino militar.

Para a compreensão de uma temática tão complexa quanto é a categoria militar, que, na definição do historiador José Murilo de Carvalho é uma categoria profissional difícil de mensurar sociologicamente, optou-se por uma metodologia de cunho interdisciplinar que possibilitasse adotar a polissemia conceitual ao invés de generalizações. Tendo como enfoque a pesquisa qualitativa, buscamos destacar da análise bibliográfica resultados válidos e representativos do fenômeno pesquisado.

A necessidade de uma ação interdisciplinar, a fim de realizar uma interligação entre a Formação Militar e a Educação em Direitos Humanos, é uma necessidade, tanto na formação dos militares das Forças Armadas Brasileiras quanto dos integrantes da área de Segurança Pública, a fim de valorizar e proteger o Estado Democrático de Direito, que tem, como um de seus fundamentos, a dignidade da pessoa humana.

${ }^{3} \mathrm{O}$ tratamento teórico que damos ao termo ethos é definido como modo de ser, numa espécie de síntese dos costumes de um povo; o termo indica, de maneira geral, os traços característicos de um grupo social específico, do ponto de vista sociocultural que o diferencia dos outros grupos, e que assim está vinculada a um valor de identidade de uma categoria social específica (NOGUEIRA, 2014, p. 72). 


\section{AS ESPECIFICIDADES DA EDUCAÇÃO E DA FUNÇÃOMILITAR}

Em 2014, completou-se 50 anos do fatídico golpe que colocou a sociedade brasileira sob o jugo dos militares. Na virada da noite de 31 de março para 10 de abril de 1964, o arbítrio da força fez calar as vozes dissonantes e ocorreram, a partir daí, graves violações dos direitos humanos. A depender do autor do discurso, aqueles acontecimentos nefastos que culminaram com uma ditadura militar que se estendeu de 1964 a 1985, podem ser tidos como uma ação política necessária para fazer frente a um avanço comunista na América Latina ${ }^{4}$ ou, ao contrário, como um golpe que, rompendo com a legalidade constitucional, destituiu do poder um presidente democraticamente eleito dentro das regras do jogo político de então, o presidente João Goulart 5 .

Após a abertura democrática ocorrida em 1985, as Forças Armadas foram colocadas numa espécie de ostracismo político, cujas funções ficaram bem delimitadas no Art. 142 da Constituição Federal de 1988.

Art. 142. As Forças Armadas, constituídas pela Marinha, pelo Exército e pela Aeronáutica, são instituições nacionais permanentes e regulares, organizadas com base na hierarquia e na disciplina, sob a autoridade suprema do Presidente da República, e destinam-se à defesa da Pátria, à garantia dos poderes constitucionais e, por iniciativa de qualquer destes, da lei e da ordem. (BRASIL, 1988).

Se, na arena política, os militares estão alijados de todo o processo decisório, em ações sociais, as Forças Armadas Brasileiras vêm

\footnotetext{
${ }^{4}$ Depois da Revolução Cubana de 1959, havia o medo do comunismo se espalhar por toda América Latina.

5 "Revolução democrática"; "Contrarrevolução"; "Golpe Militar de 64"; "Golpe civil-militar de 1964" e, mais recentemente, "Golpe civil empresarial militar de 1964" são algumas denominações encontradas na historiografia brasileira acerca dos acontecimentos políticos de 1964.
} 
tendo sua ação crescendo dia a dia ${ }^{6}$. Além das missões de intervenção direta no combate à criminalidade ${ }^{7}$, as Forças Armadas atuam nos lugares mais longínquos do País não só na missão de segurança das fronteiras nacionais, mas, sobretudo, na estabilidade social daquelas localidades. Seu emprego vai desde a construção/reconstrução e manutenção das vias de acesso (estradas e pontes), passando pela assistência médica/odontológica às populações locais até ao apoio à educação básica ${ }^{8}$.

Acrescentem-se, ainda, as diversas missões realizadas em âmbito da política externa do Brasil, como a participação das missões das Nações Unidas (ONU). Atualmente o Brasil participa e lidera a Missão das Nações Unidas para a Estabilização do Haiti (MINUSTAH) ${ }^{9}$, cede tropas para a Missão das Nações Unidas na República Democrática do Congo (MONUSCO), Missão das Nações Unidas para o referendo no Saara Ocidental (MINURSO), Missão de Paz da ONU na Libéria (UNMIL), Operação das Nações Unidas na Costa do Marfim (UNOCI), Força das Nações Unidas para Manutenção da Paz no Chipre(UNFICYP), Força Interina das Nações Unidas no Líbano (UNIFIL), Força das Nações

${ }^{6}$ Operações de Garantia da Lei e da Ordem (GLO - principalmente por ocasiões de greves das polícias militares estaduais); em Ações Cívicas Sociais (ACISO); Operações Pipa; Jornada Mundial da Juventude; Copa do Mundo de 2014, construção de poços artesianos no Nordeste, e mais recentemente no combate ao mosquito Aedes aegyptique são algumas dessas ações. Disponível em: <http://www.brasil.gov.br/ saude/2016/02/dilma-ministros- e-220-mil-militares-farao-mobilizacao-contra-o-aedes-aegypti>. Acesso em: 23 abr. 2016.

${ }^{7}$ Missões de Pacificação, como a do morro da Maré no Estado do Rio de Janeiro.

${ }^{8}$ Em muitos municípios do Norte do País, muitas vezes militares ou seus cônjuges assumem a função de professores da educação básica nas regiões fronteiriças.

${ }^{9}$ A MINUSTAH foi criada pela Resolução 1529/2004 do Conselho de Segurança da Organização das Nações Unidas após uma avaliação multidisciplinar. O Conselho de Segurança através da Resolução 1542/2004 estabeleceu a MINUSTAH por um período inicial de seis meses, a partir de 1o de junho de 2004. Disponível em: <https://ajonu.org/tag/minustah/>. Acesso em: 23 abr. 2016. 
A pedagogia militar e a formação em direitos humanos nas missões de paz: uma interdisciplinaridade necessária

Unidas de Segurança Provisória para Abyei (UNISFA), Missão das Nações Unidas no Sudão do Sul (UNMISS) ${ }^{10}$.

A finalidade constitucional das Forças Armadas é a defesa externa da Pátria, e, como instituições nacionais permanentes e regulares, elas têm seus pilares pautados na hierarquia e na disciplina e estas estão pautadas na impessoalidade. Para o sociólogo Weber (1982), a disciplina,

[...] não só elimina o carisma pessoal como também a organização baseada na honra estamental; pelo menos um de seus resultados é a transformação racional da estrutura estamental. O conteúdo da disciplina é apenas a execução da ordem recebida, coerentemente racionalizada, metodicamente treinada, e exata, na qual toda crítica pessoal é incondicionalmente eliminada e o agente se torna um mecanismo preparado exclusivamente para a realização da ordem. (WEBER, 1982, p. 292).

A disciplina é, portanto, um dos fundamentos da dominação racional metódica que caracteriza as instituições políticas e econômicas modernas. Weber (1982) busca as origens históricas da disciplina no Ocidente em duas diferentes ordens institucionais; no exército e no monastério. Já para o filósofo Foucault (1984), a rígida disciplina e a organização hierárquica são técnicas de poder que,

[...] implica uma vigilância perpétua e constante dos indivíduos. Não basta olhá-los às vezes ou ver se o que fizeram é conforme a regra. É preciso vigiá-los durante todo o tempo da atividade de submetê-los a uma perpétua pirâmide de olhares. É assim que no exército aparecem sistemas de graus que vão, sem interrupção, do general chefe até o ínfimo soldado, como também os sistemas de inspeção, revistas, paradas, desfiles, etc., que permitem que cada indivíduo seja observado permanentemente. (FOUCAULT, 1984, p. 106).

${ }^{10}$ Missões de Paz. Disponível em: <http://www.ccopab.eb.mil.br/index.php/pt/ operacoes-de-paz/missoes-em-andamento>. Acesso em: 23 abr. 2016. 
Tendo os militares essa formação tão estruturalmente delimitada pela hierarquia e disciplina, e uma vida à margem da vida social brasileira, haja vista que possuem seu próprio Sistema de Ensino, Hospitais Militares, Residências em Vilas Militares etc., a formação militar segue sendo um tabu, pois o Exército possui uma legislação educacional própria ${ }^{11}$ que o distingue do Sistema Educacional Brasileiro.

Essas especificidades são determinadas pela sua finalidade, pela estrutura organizacional de ensino, pelas relações entre os subsistemas, características estas observadas nos documentos oficiais que regulamentam o ensino militar. $\mathrm{O}$ ensino no Exército Brasileiro é regido e regulamentado por normas específicas, contudo, em consonância com o que estabelece a legislação federal. As políticas e estratégias do ensino militar são propostas pelo Estado-Maior do Exército ao Ministro de Estado que compete aprová-las e conduzi-las. (LUCHETTI, 2006, p. 117 apud NOGUEIRA, 2014, p. 89).

\section{INTERDISCIPLINARIDADE NECESSÁRIA: A EDUCAÇÃO MILITAR E A FORMAÇÃO BÁSICA EM DIREITOS HUMANOS}

\subsection{Interdisciplinaridade: apontamentos necessários}

Para Fazenda (2012), a interdisciplinaridade foi um movimento nascido na Europa, mais precisamente na França e Itália, em meados da década de 1960, resultado da ação do movimento estudantil que reivindicava novo estatuto para a universidade e para a escola. O estopim para esse movimento foi a alienação da Academia dos problemas cotidianos da sociedade, que eram encobertos e mascarados pelo que se chamava de capitalismo epistemológico de algumas ciências

${ }^{11}$ Lei Ordinária Federal n. 9.394, de 20 de dezembro de 1996, que estabelece as Diretrizes e Bases da Educação Nacional (LDB). O seu artigo 83 reza que: "O ensino militar é regulado por lei específica, admitida a equivalência de estudos, de acordo com as normas fixadas pelos sistemas de ensino (BRASIL, 1996, p. 30). 
A pedagogia militar e a formação em direitos humanos nas missões de paz: uma interdisciplinaridade necessária

e a excessiva especialização das ciências engessadas por currículos rígidos e que não deixavam margem a pensamentos e atitudes que apontassem outras direções.

O movimento tinha como concepção que o excesso de repartição das ciências ocasionaria uma falência do ser humano. Um dos principais precursores da interdisciplinaridade foi filósofo francês Georges Gusdorf (1912-2000). Gusdorf apresentou em 1961, na Unesco, um projeto de pesquisa interdisciplinar em ciências humanas, a ideia de Gusdorf era reunir um grupo de cientistas de notório saber para realizar um projeto de pesquisa interdisciplinar na área de ciências humanas.

Fazenda (2012) relata que, no Brasil, o eco dessa discussão ocorrida na Europa chega ainda no final na década de 1960, porém com sérias distorções ocasionadas por aqueles que se apressaram a aplicar o novo sem reflexão, por modismo sem medir as consequências. Um dos pioneiros a discutir, teorizar e tentar implantar a interdisciplinaridade foi Hilton Japiassú (1976), com sua obra Interdisciplinaridade e patologia do saber.

Os debates sobre a necessidade da adoção de um currículo interdisciplinar no Brasil datam da década de 1970. Fazenda (2001, p. 12 apud NOGUEIRA, 2014, p. 60) ressalta que sendo uma realidade, os países ocidentais, "[...] vêm debatendo a questão da interdisciplinaridade, tanto no que se refere à organização profunda dos currículos, à forma como se aprende, quanto à formação dos professores".

Interdisciplinaridade é o adjetivo que qualifica o que é comum a duas ou mais disciplinas ou outros ramos do conhecimento, é o processo de ligação entre as disciplinas. A interdisciplinaridade para se realizar implica a existência de um conjunto de disciplinas interligadas e com inter-relação definida, que seriam mais bem apresentadas que, de forma isolada, dispersa ou fracionada. Com o crescente desenvolvimento científico-tecnológico, originou-se o nascimento de 
diversos ramos científicos, ocasionando um fracionamento crescente dos ramos do saber, isolando-os cada vez mais, causando um distanciamento entres disciplinas correlatas.

Essa dinâmica fez com que a necessidade de integrar situações e aspectos para criar conhecimentos fosse cada vez maior. Nesse contexto, cresce a importância da interdisciplinaridade na conexão desses diversos ramos científicos, mantendo a diversidade, porém conectando a forma de aprendizagem através de atitudes, principalmente de docentes e alunos. Por outras palavras, a interdisciplinaridade é uma abordagem metodológica que consiste na busca sistemática de integração das teorias, dos instrumentos e das fórmulas de ação científica de diferentes disciplinas, com base numa concepção multidimensional dos fenômenos. Para Fazenda (2002, p. 11) "Interdisciplinaridade é uma nova atitude diante da questão do conhecimento, de abertura à compreensão de aspectos ocultos do ato de aprender e dos aparentemente expressos, colocando-os em questão".

\subsection{Comissão Nacional da Verdade: a educação militar contestada}

O currículo das escolas militares foi objeto de debate durante os trabalhos da Comissão Nacional da Verdade (CNV) ${ }^{12}$ em cujo relatório final, na parte de Conclusões e Recomendações, os relatores propõem, quanto aos processos seletivos, tanto para as Forças Armadas quanto para as Forças Auxiliares: "[5] Reformulação dos concursos de ingresso e dos processos de avaliação contínua nas Forças Armadas e na área de segurança pública, de modo a valorizar o conhecimento sobre os preceitos inerentes à democracia e aos direitos humanos" (BRASIL, 2014, p. 967).

\footnotetext{
${ }^{12}$ A Comissão Nacional da Verdade foi criada pela Lei 12.528/2011 e instituída em 16 de maio de 2012. A CNV tem por finalidade apurar graves violações de Direitos Humanos ocorridas entre 18 de setembro de 1946 e 5 de outubro de 1988 (BRASIL, 2011b).
} 
21. É necessário que a formação dos integrantes das Forças Armadas e dos órgãos de segurança pública seja precedida por processos de recrutamento que levem em conta o conhecimento dos candidatos sobre os princípios conformadores do Estado democrático de direito e sobre os preceitos teóricos e práticos relacionados à promoção dos direitos humanos. Também nos processos de avaliação contínua a que os efetivos dessas forças e órgãos são submetidos, esse conhecimento deve ser considerado, de modo a assegurar a compatibilidade de sua atuação com aqueles princípios e preceitos fundamentais. (BRASIL, 2014, p. 967).

Para a educação nacional, seja nos níveis básicos ou superiores, os relatores propõem a promoção dos valores democráticos e dos direitos humanos na educação,

\section{O compromisso da sociedade com a promoção dos direi- tos humanos deve estar alicerçado na formação educacional da população. Assim, deve haver preocupação, por parte da administração pública, com a adoção de medidas e procedi- mentos para que, na estrutura curricular das escolas públicas e privadas dos graus fundamental, médio e superior, sejam incluídos, nas disciplinas em que couberem, conteúdos que contemplem a história política recente do país e incentivem o respeito à democracia, à institucionalidade constitucional, aos direitos humanos e à diversidade cultural. (BRASIL, 2014, p. 967, grifo nosso).}

Para o Historiador Carlos Fico ${ }^{13}$, num Estado Democrático de Direito, é primordial que a sociedade brasileira tenha ciência do que está sendo ensinado no interior das Academias e Colégios Militares. A sociedade brasileira não pode ficar à margem de como estão sendo formados aqueles que são os responsáveis por salvaguardas, tanto a Constituição quanto as Instituições Democráticas Brasileiras.

${ }^{13}$ Professor Doutor do Programa de Pós-Graduação em História da Universidade Federal do Rio de Janeiro. 
Em consonância com aquele historiador, os relatores da Comissão Nacional da Verdade acataram os pareceres dos especialistas que fizeram parte dos estudos atinentes à educação militar e propuseram que haja uma modificação do conteúdo curricular das academias militares e policiais, para promoção da democracia e dos direitos humanos.

22. O conteúdo curricular dos cursos ministrados nas academias militares e de polícia deve ser alterado, considerando parâmetros estabelecidos pelo Ministério da Educação (MEC), a fim de enfatizar o necessário respeito dos integrantes das Forças Armadas e dos órgãos de segurança pública aos princípios e preceitos inerentes à democracia e aos direitos humanos. Tal recomendação é necessária para que, nos processos de formação e capacitação dos respectivos efetivos, haja o pleno alinhamento das Forças Armadas e das polícias ao Estado democrático de direito, com a supressão das referências à doutrina de segurança nacional. (BRASIL, 2014, p. 968).

Dentro desse contexto, importante se faz que os efetivos militares tenham uma educação interdisciplinar que conjugue a Formação Militar com a Formação em Direitos Humanos, haja vista que os integrantes das Forças Armadas cumprem um papel importantíssimo, tanto no que diz respeito as ações internas de garantia da lei e da ordem, quanto as missões no exterior. A relevância deste artigo está no fato de tentar introduzir, na esfera acadêmica, essa discussão premente sobre a importância de uma formação dos agentes que são servidores públicos que, segundo Weber, possuem o monopólio legítimo do uso da força física (WEBER, 1982).

Segundo o Filósofo francês Louis Althusser (1918-1990), o Estado deve ser compreendido como a superestrutura da sociedade, composta pelos Aparelhos repressivos e os Aparelhos ideológicos de Estado. Nesse sentido, a instituição Forças Armadas figura como Aparelho Repressivo do Estado, em que "Repressivo indica que o 
A pedagogia militar e a formação em direitos humanos nas missões de paz: uma interdisciplinaridade necessária

Aparelho de Estado em questão "funciona pela violência", pelo menos no limite (porque a repressão, por exemplo administrativa, pode revestir formas não físicas) (ALTHUSSER, 1985, p. 43).

Althusser (1985) classifica de distinção fundamental: o Aparelho repressivo de Estado "funciona pela violência", enquanto os Aparelhos Ideológicos de Estado funcionam "pela ideologia". Dentro da perspectiva teórica de Althusser, qualquer Aparelho de Estado, seja de repressivo, seja ideológico, funciona simultaneamente pela violência e pela ideologia. É que, em si mesmo, o Aparelho (repressivo) de Estado funciona prevalentemente pela repressão (inclusive física), embora funcione secundariamente pela ideologia, não havendo aparelho puramente repressivo. Assim, tanto o Exército quanto as Polícias funcionariam também pela ideologia, simultaneamente para assegurar a sua própria coesão e reprodução dos valores que projetam no exterior, pois os Aparelhos Ideológicos de Estado funcionam de um modo massivamente prevalente pela ideologia, embora funcionando secundariamente pela repressão, mesmo que no limite, mas apenas no limite, esta seja bastante atenuada, dissimulada ou até simbólica. Não há aparelho puramente ideológico.

A escola, seja ela civil ou militar, é um espaço dinâmico político por excelência. Ela é politicamente determinada, seu processo educativo é político e os seus resultados também são políticos. Assim ela exprime as relações de força vigentes na sociedade. (LUDWIG, 1998, p. 7, grifos do autor).

As instituições militares precisam adequar-se às demandas do século XXI, tanto do ponto de vista político quanto do social, haja vista que são as principais instituições que, em última instância, salvaguardam todas as prerrogativas institucionais dentro da vigência de um Estado democrático de Direito. Conjugar na prática pedagógica militar ações de interdisciplinaridade, cujos objetivos são a formação de um profissional comprometido com seus deveres institucionais, 
mas, acima de tudo, com sua própria cidadania, pois como temos visto nas recentes propagandas institucional do Exército, “O militar é um cidadão como qualquer outro"14 e, nesse sentido, ele deve possuir uma educação plural, condizente com o atual quadro do Estado Democrático de Direito; uma educação crítica reflexiva que o possibilite entender a complexidade da realidade brasileira compreendendo-se como um protagonista de direitos e deveres, instrumentalizando-o para a compreensão do seu estar no mundo com os outros.

Para tanto, necessário se faz que o currículo das escolas de formação militares sejam objetos de pesquisa da comunidade acadêmica, para que juntos, todos, militares e sociedade brasileira, possam repensar suas práticas e atualizar sua metodologia em consonância com o atual momento democrático que se encontra a sociedade brasileira. Acreditamos que matérias como Sociologia, Filosofia e Direitos Humanos são essenciais para se pensar nesse "novo" militar que a sociedade moderna demanda. Um profissional das armas em sua finalidade precípua, mas, antes de tudo, um profissional com uma formação humana e com total compromisso com ordem democrática. A própria Lei de Diretrizes e Bases da Educação Nacional, Lei 9.394/96, já faz alusão para essa formação consciente a partir do Ensino Médio, em que,

A Lei 9.394/96 estabelece como uma das finalidades centrais do
Ensino Médio a construção da cidadania do educando, eviden-
ciando, assim, a importância do ensino da Sociologia no Ensino
Médio. Tendo em vista que o conhecimento sociológico tem
como atribuições básicas investigar, identificar, descrever,
classificar e interpretar/explicar todos os fatos relacionados
à vida social, logo permite instrumentalizar o aluno para

${ }^{14}$ Propaganda veiculada diariamente, em horário nobre, numa das maiores redes de televisão brasileira, a Rede Globo, com o intuito de reaproximar os militares da sociedade civil. 
A pedagogia militar e a formação em direitos humanos nas missões de paz: uma interdisciplinaridade necessária

que possa decodificar a complexidade da realidade social. (BRASIL, 2000, p. 318, grifos nossos).

Segundo a UNESCO, a busca pelo desenvolvimento humano sustentável e equitativo forma, concomitantemente, a democracia, a cultura da paz e a equidade quanto às questões de gênero e idade. Nesse sentido, os quatro pilares do conhecimento são: aprender a ser; a fazer; a conviver e a conhecer. Para o militar que queremos, precisamos não só saber o que se passa por detrás dos muros da caserna, mas que as portas da caserna sejam abertas para toda a sociedade brasileira.

É importante que a comunidade acadêmica possa não só pesquisar, mas opinar sobre os rumos que a pedagogia militar esteja tomando, até porque temos um fenômeno educacional que vem preocupando os especialistas em educação, que é a crescente militarização da educação básica brasileira, na qual, em vários estados brasileiros, escolas públicas vêm se "transformando" em Colégios Militares, como no caso recente do Estado de Goiás. No Brasil, o número de escolas básicas públicas geridas pelas Polícias Militares já chega a 93 instituições. O Estado que mais possui escolas assim em todo o país é o Estado de Goiás, onde a Secretaria de Educação ${ }^{15}$, recentemente, anunciou que várias escolas públicas estaduais ainda passarão a ser administradas pela Polícia Militar, como foi o caso da Escola Estadual Fernando Pessoa, em Valparaíso.

No início do 2으 semestre de 2015 foram mais oito colégios que voltaram às aulas naquele estado nesses moldes. Atualmente apenas nove estados brasileiros não possuem colégios de educação básica públicos geridos pelas Polícias Militares. Goiás passou a ser o líder no

${ }^{15}$ Há que se ressaltar a diferença entre os Colégios das Polícias Militares e das Escolas Públicas que estão passando para a gestão militar. Disponível em: <http:/ colegiomilitarhugo.g12.br>. Acesso em: 13 fev. 2014. 
quesito, com 26 escolas nesse formato (2015), seguido de perto por Minas Gerais, que possui 22 colégios militares ${ }^{16}$.

Essa influência das especificidades do ensino militar no ensino público brasileiro suscita algumas perguntas: Onde começa a "militarização" dos alunos e onde termina o ato de educar? Quais os limites que separam estas práticas? Há limites? Se há, eles são respeitados? Esse ambiente permeado pelo ethos militar permite a formação de cidadãos críticos e autônomos? Como nos diz o Filósofo Immanuel Kant ${ }^{17}$, "O homem não é nada além daquilo que a educação faz dele".

\section{AS CARACTERÍSTICAS DA SOCIEDADE E DO ESPÍRITO MILITAR}

A sociedade Militar tem um caráter de sociedade fechada, por seu particularismo e seu isolamento dentro da comunidade nacional, definindo assim sua essência. É uma sociedade composta por membros de diferentes seguimentos da escala social, de diversas regiões do país, com costumes e culturas diferentes. Essa sociedade é constantemente chamada de "Família Militar", cujos laços são formados com a convivência diária de seus membros, e pelo exercício de um dos atributos mais importante, senão o mais importante, o qual o militar deve possuir e exercitá-lo diariamente, qual seja, a lealdade. Seja essa lealdade devotada a seus companheiros e principalmente com a Pátria.

Para Girardet (2000), os membros da sociedade militar possuem

\footnotetext{
${ }^{16}$ Cresce o número de escolas básicas públicas geridas pela Polícia Militar: Modelo de colégios geridos pela Polícia Militar está em expansão no país. Jornal Folha de São Paulo. Em números: GO (26), MG (22), BA (13), RS (7), AM (4), MA (3), TO (2), RO (2), SC (2), CE(2), PI (2) e PE (2). Disponível em: <http://www1.folha.uol.com. br/educacao/2015/08/1666631-cresce-no-brasil-o-numero-de-escolas-basicaspúblicas-geridas-pela-pm.shtml>. Acesso em: 14 maio 2016.

${ }^{17}$ Immanuel Kant (1724-1804) foi um Filósofo prussiano. Amplamente considerado como o principal filósofo da era moderna.
} 
A pedagogia militar e a formação em direitos humanos nas missões de paz: uma interdisciplinaridade necessária

um sentimento de estar participando de uma ordem, no sentido mais antigo dessa palavra. Para Girardet, essa sociedade, realmente se comporta com uma:

[...] família em que a autoridade era mais ou menos paterna e que tinha seu caráter próprio impresso por seu chefe ou por um antigo coronel mais temido ou mais amado que seus antecessores. Mas todos os regimentos possuíam em comum o espírito militar e, se é possível expressar assim, o espírito antiburguês. (GIRARDET, 2000, p. 63),

Uma das cerimônias mais emblemáticas e de maior simbolismo na caserna é o ato da incorporação. Nesse ato solene, celebrado pela instituição, ao incorporar um "civil" às suas fileiras, passando a chamar- Ihe de soldado, a instituição passa para ele a mensagem de que, a partir dessa data, será ele separado da massa de seus concidadãos, sendo incluído em uma nova ordem. A condição de soldado o coloca em um plano moral diferente dos demais, passando a impor às suas consciências outras exigências, submetendo-lhe a outras leis, em geral mais rigorosas, e pedindo-Ihe, em nome do Estado, o sacrifício da própria vida.

As próprias características dos Exércitos, para Girardet (2000), concorrem para o isolamento dos seus integrantes dos demais cidadãos da nação, "[...] leis particulares, tradições, usos e até preconceitos habilmente preservados tendem para o mesmo fim: quebrar todos os vínculos que unem o Exército à sua fonte, todos, até os mais tenazes" (GIRADET, 2000, p. 64). As Forças Armadas Brasileiras são instituições nacionais permanentes e regulares, organizadas com base na "hierarquia" e na "disciplina".

Segundo Ludwig (1998), a educação militar no Brasil tem por propósito formar um aplicador da violência estatal adequado ao jogo de forças existente no seio da sociedade capitalista, para isso utiliza um ethos apropriado para atingir esses fins. Para adequar-se ao modo 
de ser militar, o soldado precisa conhecer a biografia da Pátria e dos seus heróis, não apenas para cultuar essas personalidades, mas para deixar-se envolver por seu espírito de renúncia e sua tenacidade. A profissão militar tem na lealdade uma de suas virtudes mais importantes, essa lealdade deve ser cultivada em relação a seus companheiros e principalmente em relação ao Estado.

Definir o significado de ethos não é tarefa fácil e muito menos exata. Nogueira (2014) define ethos como um conjunto de valores que orientam o comportamento do homem em relação a outros homens na sociedade em que vive, a fim assegurar a convivência harmônica na consecução do bem-estar social dessa dada sociedade. É um modo de ser, uma espécie de síntese dos costumes de um povo, indica os traços característicos de um grupo social específico do ponto de vista sociocultural em diferença a outros grupos. Desse modo, forma uma identidade social de uma determinada categoria social.

Em sociologia e antropologia, ethos são referentes aos costumes e traços comportamentais que distinguem um povo, uma nação, uma cultura. O ethos pode exprimir um conjunto de valores característicos de um movimento cultural ou artístico de qualquer natureza. Nogueira (2014) assevera que, para alguns filósofos, ética e ethos são tratados como sinônimos e, para outros, ethos é tratado com a derivação de ética, citando o conceito etimológico do termo ethos adotado Chauí (2003, p. 320 apud NOGUEIRA, 2014, p. 69).

Na língua grega existem duas vogais para pronunciar e grafar nossa vogal e: uma vogal breve, chamada épsilon, e uma vogal longa chamada eta. Éthos, escrita com a vogal longa, significa costume; porém, se escrita com a vogal breve, éthos, significa caráter, indole natural, temperamento, conjunto das disposições físicas e psíquicas de uma pessoa. Nesse segundo sentido, éthos se refere às características pessoais de cada um, as quais determinam que virtudes e que vícios cada indivíduo é capaz de praticar. 
A pedagogia militar e a formação em direitos humanos nas missões de paz: uma interdisciplinaridade necessária

O ethos militar é introjetado na personalidade do militar através das práticas rotineiras e eminentemente militares, como os discursos oficiais, as falas dos comandantes e superiores hierárquicos que são assimiladas prontamente, sem questionamentos pelos subordinados sob pena de ferir de morte os pilares de sustentação das instituições militares, qual seja, a hierarquia e a disciplina, que são fundamentos da carreira militar, os pilares de sustentação de todas as ações de comandantes e comandados. Esses valores são marcados na alma do soldado pelo culto às tradições militares, aos vultos militares e aos símbolos nacionais como, a bandeira e o hino nacional.

Uma melhor compreensão do que seja esse ethos militar é expressa no Vade-Mécum de Cerimonial Militar do Exército-Valores, Deveres e Ética Militares, o qual traz as principais "ideias-força” referentes aos valores, deveres e ética militares, visando a contribuir para o continuado aprimoramento das virtudes militares. O referido VadeMécum apresenta como valores a serem cultuados diuturnamente pelos militares, o patriotismo, o civismo, a fé na missão do Exército, o amor à profissão, o espírito de corpo e o aprimoramento técnicoprofissional. Já a carreira militar não deve ser encarada como uma simples ocupação, um emprego, deve ser encarada como um ofício exclusivista e absorvente, dos mais nobres e necessários à defesa e segurança Pátria:

A carreira militar não é uma atividade inespecífica e descartável, um simples emprego, uma ocupação, mas um ofício absorvente e exclusivista, que nos condiciona e autolimita até o fim. Ela não nos exige as horas de trabalho da lei, mas todas as horas da vida, nos impondo também nossos destinos. A farda não é uma veste, que se despe com facilidade e até com indiferença, mas uma outra pele, que adere à própria alma, irreversivelmente para sempre. (BRASIL, 2002).

Para Castro (2004), o processo de construção da identidade social e do espirito militar foi forjado através de um intenso processo de socialização profissional militar, que ocorre em relativo isolamen- 
to ou autonomia, diferente das demais socializações profissionais. Esse processo contribui para uma grande coesão e homogeneidade da caserna, o chamado no meio militar de "espírito-de-corpo". Esse processo causa para as instituições militares um alto preço, o distanciamento entre os militares e o mundo civil.

Castro (2004), cita que, para Berger e Luckmann, o processo de socialização militar é de natureza tão intensa que o indivíduo acaba "mudando de mundos". Para Vidich e Stein, o processo de ensino aprendizagem para a criação de um soldado é como se houvesse uma "dissolução" de sua identidade anterior de "civil" e a criação de uma nova identidade, a de militar:

Revela a tentativa de romper com os antigos valores e sensibilidades civis, para implantar mais facilmente uma estrutura de caráter o mais novo possível. É essa tentativa de romper a sensibilidade adquirida que determina a "domesticação" do recruta, e a atribuição, a ele, de uma posição muito inferior no mundo militar. Ele deve perder grande parte de sua identidade anterior para que então se torne consciente de sua personalidade em termos de seu papel militar. (CASTRO, 2004, p. 35).

A Educação Militar possui especificidades necessárias para formar e preparar o militar para ser empregado em situações quase sempre extremas, seja em atuação interna ou externa, o que justifica um ethos próprio que visa introjetar no soldado um conjunto de valores composto pelo culto às tradições, vultos e aos símbolos nacionais. A introjeção desses valores durante a formação do militar tem por objetivo criar o Espirito Militar. São valores que devem ser cultuados, porém devem sempre se subordinar aos predicados do Estado Democrático de Direito, que tem como um de seus fundamentos a dignidade da pessoa humana, conforme previsto na Constituição Federal de 1988. 


\subsection{A educação militar no Brasil - origem e evolução}

Constitucionalmente a educação no Brasil passou a ser um direito do povo e um dever do Estado e da entidade familiar após a Constituição Brasileira de 1934, promulgada pela Assembleia Nacional Constituinte, em seu Capítulo II, artigo 149. Verifica-se que a história do Exército Brasileiro se confunde com a trajetória da construção e da consolidação do Brasil como nação independente e da construção de nossa identidade nacional. Para Nogueira (2014), o processo evolutivo da educação militar no Brasil pode ser dividido em duas fases, a saber: a primeira anterior à transferência da Família Real Portuguesa para o Brasil (1699 a 1808), período em que o ensino era ministrado de forma precária e improvisada. Já na segunda fase, que começou com a chegada da Corte Portuguesa e da Família Real em janeiro de $1808^{18}$, demandou o planejamento de uma grande reestruturação do Exército, visando formar uma força militar mais eficiente e menos amadora, a fim de garantir a segurança da corte.

Luchetti (2006) pontua que o ensino militar no Brasil Colônia era precário, e as aulas eram ministradas de forma avulsa e descentralizada. O primeiro núcleo de formação de ensino militar no Brasil foi o Curso Prático de Fortificação instalado em 1699 na cidade do Rio de Janeiro. Para Ludwig (1998), o processo de formação dos militares no decorrer da história brasileira tem contribuído para forjar indivíduos com perfil ideológico baseado na doutrina de segurança nacional, idealizada pela Escola Superior de Guerra, que visava formar um oficial com perfil ideológico autoritário e com tendências intervencionistas.

\footnotetext{
${ }^{18}$ No século XIX Napoleão Bonaparte tornou-se soberano do império da França, tendo como objetivo apoderar- se de toda a Europa. Naquele momento da história, Portugal era governado Dom João. Portugal e Inglaterra eram velhos cúmplices, o que deixou Dom João em uma posição delicadíssima com relação a Napoleão. A saída encontrada, em conluio com os ingleses, foi a mudança da Corte Portuguesa para a então Colônia. Em novembro de 1807, sob proteção da força naval inglesa, D. João, sua linhagem e a nobreza que o rodeava mudaram-se para o Brasil.
} 
Para Ludwig (1998), o processo de ensino-aprendizagem da oficialidade brasileira, aqui incluída a Marinha e a Aeronáutica, está voltado para produzir um profissional aplicador da violência adequado ao jogo político de forças existentes na sociedade brasileira, estando, de um lado, a classe dominante, a burguesia nacional, liderada pela indústria, extremamente preocupada com sua sobrevivência, em busca de lucros imediatos e benefícios estatais, por outro lado, essa mesma burguesia nutre imenso medo da organização do povo, principalmente quando ele se organiza em sindicatos, partidos e associações. Do outro lado, há a classe dominada, o povo brasileiro, historicamente desprotegida, espoliada, raramente protegida e constantemente cerceada em suas manifestações por melhores condições de vida.

Ao longo da história do Brasil, a educação brasileira passou por diversas reformas educacionais, sendo que a educação militar se manteve à margem desse processo como nos mostra Rodrigues (2008, p. 14),

[...] as reformas no sistema de ensino militar em nenhum momento acompanharam qualquer reforma de ensino feita no país, principalmente a reforma de 1931, de Francisco Campos e a de 1942, de Gustavo Capanema, que não fizeram qualquer ingerência no ensino militar do Brasil. Ao contrário, causaram um isolamento com relação ao sistema de ensino civil e problemas de equiparação nas estruturas do ensino militar e civil brasileiro, que até hoje permanecem.

\subsection{Um breve e necessário histórico dos direitos humanos}

Para Gutierres e Urquiza (2013), os primeiros registros sobre os direitos humanos (DH) aconteceram entre 1792-1750 a.C, na Babilônia onde foi estabelecido o Código de Hamurabi ${ }^{19}$. O referido código tinha

${ }^{19}$ É chamado Código de Hamurabi uma compilação de 282 leis da antiga Babilônia (atual Iraque), composto por volta de 1772 a.C. Disponível em: <http://www.infoescola.com/historia/codigo-de-hamurabi/>. Acesso em: 23 abr. 2016. 
A pedagogia militar e a formação em direitos humanos nas missões de paz: uma interdisciplinaridade necessária

como propósito articular diferentes interesses, pessoas, estruturas e tradições naquele império. Nessa época específica, a ideia de DH e de justiça tinham um sentido de retribuição, levando o estabelecimento de leis severas e punições desproporcionais e injustas.

Sobre os antecedentes históricos dos Direitos Humanos, Comparato (2010, p. 62) afirma que o artigo I da Declaração de Independência Americana "É o registro de nascimento dos Direitos Humanos na História [...]", vindo a consolidar a ideia de igualdade entre os homens, também presente na Declaração dos Direitos do Homem e do Cidadão, de 1789.

Um marco para os DH foi a criação, em 24 de outubro de 1945, da Organização das Nações Unidas (ONU), no pós-Segunda Guerra Mundial, em virtude da necessidade urgente de se buscar a paz mundial. A criação da ONU foi ratificada pela China, Estados Unidos, França, Reino Unido, União Soviética, Brasil e vários outros países, totalizando 50 membros. Conta atualmente com 193 países membros. A criação da organização foi inspirada na antiga Liga das Nações, criada com o término da Primeira Guerra Mundial pelo Tratado de Versalhes de $1919^{20}$.

O processo histórico da evolução dos $\mathrm{DH}$ deve ser entendido como um processo advindo principalmente de lutas entre poderes e contra poderes. Nesse sentido, Bobbio (1992, p. 5) afirma que,

[...] os direitos do homem, por mais fundamentais que sejam, são direitos históricos, ou seja, nascidos em certas circunstâncias, caracterizados por lutas em defesa de novas liberdades

\footnotetext{
${ }^{20}$ Foi um tratado de paz que determinou os termos de paz na Europa pondo fim oficialmente à Primeira Guerra Mundial. A data de sua assinatura é 28 de junho de 1919 e teve lugar na cidade de Versalhes, antiga residência do monarca da França. Além do acerto da paz entre os beligerantes, esse documento abordava também a criação da Liga das Nações, organização destinada a promover a paz e a prevenir conflitos entre seus membros. Disponível em: <http://www.infoescola.com/historia/ tratado-de-versalhes/>. Acesso em: 23 abr. 2016.
} 
contra velhos poderes, e nascidos de modo gradual, não todos de uma vez e nem de uma vez por todas.

Fruto da evolução histórica ocorrida ao longo dos anos, nasceu a Declaração dos Direitos Humanos, aprovada pela Assembleia Geral das Nações Unidas, em 10 de dezembro de 1948, que consagra o direito de todo homem de ser reconhecido como pessoa. Considera que o reconhecimento da dignidade inerente a todos os membros da família humana e dos seus direitos iguais e inalienáveis constitui o fundamento da liberdade, da justiça e da paz no mundo. A declaração traz um rol mínimo de direitos a ser observado na defesa do ser humano.

Os DH possuem características mencionadas pela doutrina de direitos humanos. Destacamos aqui o caráter inalienável e irrenunciável - ambos se voltam à pessoa humana à margem de seu consentimento ou até contrariamente a ele. A universalidade, mutabilidade, a imprescritibilidade e a inviolabilidade são tradicionalmente consideradas características dos direitos humanos, pois eles, respectivamente, não se perdem por decurso do prazo nem podem ser desrespeitados por indivíduos ou autoridades públicas.

Para o objetivo aqui proposto, onde uma tropa de paz atua em um país estranho que possui leis próprias, a característica das mais importantes seria, a nosso ver, o da universalidade dos $\mathrm{DH}$. A universalidade dos DH foi discutida e aprovada pela ONU na Convenção de Viena, em 1993. Durante a Convenção, foram elaborados e aprovados por consenso a Declaração e o Programa de Ação de Viena, que incorporou como um de seus princípios o caráter universal dos direitos humanos, convertendo também o direito ao desenvolvimento em direito universal e parte integrante dos direitos humanos, além de enfatizar o empenho para que se alcançasse um estágio efetivo de cooperação internacional, conforme artigo 5․ . 


\subsection{A participação do Brasil em missões humanitárias de paz}

A participação brasileira em missões de paz da ONU, se dá através dos preceitos da política externa adotada pelo Brasil e se baseia no artigo 4음 da Constituição da Federal de 1998, após obedecidas algumas condicionantes, das quais a principal é a aceitação, por parte dos países ou das facções envolvidas no conflito, da presença de observadores ou tropas estrangeiras em seu território. A primeira participação do Brasil em missões de paz ocorreu em 1947, quando observadores militares foram enviados para os Balcãs ${ }^{21}$. Depois, durante as décadas de 1950 e 1960, o Brasil participou com efetivos maiores, integrando forças internacionais de paz, sob a ONU no Oriente Médio e da Organização dos Estados Americanos no Caribe. A mais longa missão foi no Oriente Médio (UNEF) e durou de 1957 a 1967, com a participação de 600 homens, em média, que se revezaram em 20 contingentes.

\subsection{A MINUSTAH}

A operação de manutenção da paz multidimensional das ONU, atualmente em andamento no Haiti, foi aprovada pela Resolução 1.542 do Conselho de Segurança das Nações Unidas (CSNU), em 30 de abril de 2004. Fundamentou-se no pedido oficial realizado pelo presidente interino do país, Boniface Alexandre, para que a ONU auxiliasse na manutenção da segurança interna e no apoio a uma transição política pacífica no país.

A ONU anteriormente já atuara no Haiti ${ }^{22}$, quando constatou a incapacidade do país em se organizar politicamente e em proporcio-

${ }^{21}$ Disponível em: <http://www.brasil.gov.br/governo/2012/04/brasil-participa-de-missoes-de-paz-desde-1947>. Acesso em: 23 abr. 2016.

${ }^{22}$ O Haiti é a segunda maior ilha das Grandes Antilhas no Mar do Caribe. O País possui superfície de $27.750 \mathrm{~km}^{2}$, e seus limites são: Oceano Atlântico ao Norte, República Dominicana a Leste, Mar do Caribe ao Sul e passagem de Sotavento a 
nar as adequadas condições de vida do povo. A Missão das Nações Unidas no Haiti (UNMIH) perduraria até o ano de 1996, tinha como objetivo reinstalar a democracia e assegurar a realização das eleições. Antes da MINUSTAH aconteceram mais quatro missões na tentativa de concretizar os objetivos da ONU, a Missão de Apoio da ONU no Haiti (UNSMIH), Missão da ONU de Transição do Haiti (UNTMIH), e a Missão da Polícia das Nações Unidas no Haiti (MIPONUH).

A MINUSTAH foi criada pela Resolução 1.529/2004 ${ }^{23}$ do CSNU, após uma avaliação multidisciplinar. A Resolução 1.542/2004 estabeleceu a MINUSTAH por um período inicial de seis meses, a partir de 1 o de junho de 2004, cujo objetivo era garantir a estabilidade durante a vacância de poder no Haiti, decorrente da saída de Jean-Bertrand Aristide. Atualmente está no Haiti, o 24으 Contingente Brasileiro (CONTIBRAS) para o cumprimento de seis meses de missão ${ }^{24}$.

\section{A PREPARAÇÃO DO CONTINGENTE BRASILEIRO PARA A MINUSTAH - OPORTUNIDADE PARA UMA EDUCAÇÃO INTERDISCIPLINAR}

A seleção e o preparo do CONTIBRAS são regulados pelo Comandante de Operações Terrestres (COTER) ${ }^{25}$, Órgão de Direção

Oeste. Sua capital é Porto Príncipe, e o francês e crioulo são os idiomas oficiais. O catolicismo constitui-se na religião oficial mas a influência africana é marcante em práticas místicas como o vodu. Disponível em: <http://www.eb.mil.br/web/haiti/ histórico>. Acesso em: 23 abr. 2016.

${ }^{23}$ Disponível em: <https://ajonu.org/tag/minustah/>. Acesso em: 23 abr. 2016.

${ }^{24}$ Disponível em: <http://www.ccopab.eb.mil.br/index.php/pt/ccopab/noticias-do-centro/2016/820-ccopab- inicia-eaop-do-brabat-24>. Acesso em: 23 abr. 2016.

${ }^{25}$ Criado pelo decreto n. 99.699, de 06 de novembro de 1990. Suas instalações foram inauguradas em 07 de janeiro de 1991, no Quartel-General do Exército, sediado em Brasília/DF. A partir de 1으 de janeiro de 2003, o COTER passou a ter autonomia administrativa, antes vinculada ao Estado-Maior do Exército, a qual Ihe foi concedida por meio da Portaria n. 286-Cmt Ex, de 25 de junho de 2002. 
A pedagogia militar e a formação em direitos humanos nas missões de paz: uma interdisciplinaridade necessária

Setorial (ODS) do Exército Brasileiro, responsável pela preparação de militares e civis designados para missão de paz no exterior. Através da Diretriz de Preparação Específica de Tropa de Missão de Paz, datada de 10 de julho de 2015, o COTER regulou a seleção e a preparação do 24 은 CONTIBRAS que atualmente se encontra no Haiti, desde 19 de junho de 2016.

A metodologia de preparação da tropa é feita observando a instrução "por nível". Dessa forma, os oficiais recebem os conhecimentos específicos através de estágios, diretamente no Centro Conjunto de Operações de Paz do Brasil (CCOPAB) ${ }^{26}$. Capitães e tenentes integrantes do contingente são preparados como instrutores de corpo de tropa. Os conhecimentos auferidos pelos oficiais são repassados às praças pré-selecionadas, de forma descentralizadas em polos de instrução.

A preparação específica é complementada pela realização do Exercício Básico de Operações de Paz (EBOP), conduzido pelo Batalhão de Infantaria de Força de Paz Haiti (BRABAT), com o objetivo de adestrar e nivelar conhecimentos às tropas níveis Grupos e Pelotão. Já o Exercício Avançado de Operações de Paz (EAOP) conduzido pelo CCOPAB em até duas semanas tem por objetivo certificar, na 1 a fase, as tropas níveis Grupos de Combate e Pelotão e, na 2a fase, os níveis Subunidade e Batalhão incluindo diversas Seções de Estado-Maior.

É realizada também uma criteriosa avaliação psicológica da tropa pelo Centro de Estudos de Pessoal (CEP) ${ }^{27}$. Essa avaliação visa levan-

${ }^{26}$ Criado pelo Ministério da Defesa em 15 de junho de 2010, a portaria no 952MD, com a finalidade de preparar militares e civis brasileiros e de nações amigas a serem enviados em missões de paz e de buscar uma maior integração entre as três Forças. Disponível em: <http://www.ccopab.eb.mil.br/index.php/pt/ccopab/ criacao-do- centro>. Acesso em: 23 abr. 2016.

27 É uma instituição de ensino do Exército Brasileiro. Mais do que uma escola, comporta áreas diversificadas, vetores de sua atuação: Ensino, Pesquisa, Avaliação Psicológica e Preservação Ambiental e Histórica. Mantém, também, relacionamento com diversos públicos e segmentos da sociedade, como estabelecimentos de 
tar dados e apresentar subsídios para assessoramento do processo de seleção, levando em consideração o perfil exigido para a missão. Detectar e antecipar soluções para eventuais questões individuais e de relacionamento pessoal, familiar que possa ocorrer durante ou após o término da missão.

A avaliação e a preparação física dos integrantes do CONTIBRAS são realizadas pelo Instituto de Capacitação Física do Exército $(\text { IPCFEx })^{28}$. Cabe ao IPCFEx planejar o treinamento físico para ser executado pelos integrantes da missão. Ao início e final do período de instrução, o coordenador de preparo do BRABAT realiza uma avaliação física completa para permitir uma aferição da evolução da capacidade física da tropa e o estabelecimento de um banco de dados do desempenho físico do pessoal selecionado.

A Diretriz de Preparação prevê estágios na cidade de Brasília, DF, e Rio de Janeiro, RJ, com a finalidade de difundir e nivelar conhecimento, dentre os quais: Comunicação Social para Missão de Paz; Comando e Controle; Inteligência; Assessoria Jurídica; Instrução de Operação e Manutenção Básica do Portal de Inteligência Operacional; Tradutores e Intérpretes Militares; Preparação de Comandantes e Oficiais de Estado-Maior em Operações de Paz; Preparatório para Comandantes de Subunidade e Pelotão; Coordenação Civil-Militar; e Patrimônio.

Existem também os estágios de instrução para o desempenho de funções específicas como: Coordenação do Apoio Logístico ao Contingente; Emprego do Destacamento de Operações de Paz e

ensino, empresas, dentre outros, ultrapassando as atividades exclusivamente de âmbito militar.

${ }^{28}$ O Instituto de Pesquisa da Capacitação Física do Exército e subordinado ao Centro de Capacitação Física do Exército tem como missão: dentre outras atribuições desenvolver pesquisas de capacitação física ligadas às áreas de Avaliação Física, Biomecânica, Bioquímica, Cardiologia, Cineantropometria, Fisiologia do Exercício, Termorregulação, Nutrição, Psicofisiologia e Treinamento Desportivo para solução de problemas de interesse do Exército. 
A pedagogia militar e a formação em direitos humanos nas missões de paz: uma interdisciplinaridade necessária

Destacamento de Apoio a Inteligência; Operadores de equipamentos mecanizados; e confecção de passaporte.

Nas Prescrições Diversas da Diretriz de Preparação, prevê-se que, durante a fase final da preparação, serão ministradas instruções sobre exploração sexual, que aborda a construção de estratégia de enfrentamento da violência baseada em gênero no contexto humanitário, atendendo a Resolução n. 1325/2000 ${ }^{29}$, do CSNU, e a proteção da criança e adolescente, a cargo do COTER.

\section{CONSIDERAÇÕES FINAIS}

Nosso trabalho pretendeu buscar indícios das especificidades da educação (formação) militar destacando sua relevância dentro de um Estado Democrático de Direito. Nesse sentido, a constatação da inexistência de um currículo que privilegie a temática Direitos Humanos e Democracia afeta a formação daqueles que, em última instância, possuem a incumbência da salvaguarda da Ordem Institucional.

O Ministério da Defesa elaborou, em 2011, o Manual de Emprego do Direito Internacional dos Conflitos Armados nas Forças Armadas (MD34-M-03), com a finalidade de ser o instrumento normativo na difusão, estudo e consulta, nas situações previstas de planejamento e emprego conjunto e ou singular dos Comandos Operacionais ativados nas diversas situações de conflitos armados internacionais e não internacionais, e também em outras atividades inerentes ao emprego constitucional das Forças Armadas, no que se refere ao DICA (BRASIL, 2011a).

Em que pese ao referido manual apenas tratar do DICA conforme explicitado, entendemos que se aplicam também os preceitos dos $\mathrm{DH}$

\footnotetext{
${ }^{29}$ Resolução 1.325 trata sobre mulheres, paz e segurança. Ela exige a participação das mulheres na construção da paz, a proteção das violações dos direitos humanos, e a promoção do acesso à justiça e aos serviços para enfrentar a discriminação. Disponível em: <http://www.onumulheres.org.br/areas-tematicas/paz-e-seguranca/>. Acesso em: 23 abr. 2016.
} 
na ação do da MINUSTAH, por terem preceitos de caráter inalienável, irrenunciável, universal, imutável, imprescritível e inviolável. Constatase a necessidade do estabelecimento de uma formação específica DH para os militares e civis do CONTIBRAS selecionado para compor a MINUSTAH, bem como outros ramos do direito afetos a conflitos armados de natureza interna e externa dos países, tendo em vista a atuação em um país com cultura e costumes diferentes.

Essa formação seria viável através de parcerias com Instituições Civis de Ensino Superior, cujos especialistas estão mais aptos a preparar a tropa sobre a história dos países em que atuarão, noções básicas de direito internacional, noções gerais sobre a cultura, hábitos, tradições, além de um preparo mínimo sobre o idioma e dialetos falados naqueles países. Essa seria mais uma oportunidade de as Forças Armadas quebrarem esse estigma que as acompanha por causa de sua tradição intervencionista ao longo da história do Brasil. E necessário que as Forças Armadas saiam desse ostracismo e invisibilidade civil em que se encontra.

Percebemos que a seleção e treinamento do 24을 CONTIBRAS tiveram uma preparação bastante seccionada e descentralizada dos militares que atuaram na missão humanitária no Haiti. Pelas características sociais, políticas, culturais e econômicas do país caribenho, faz-se necessária uma preparação interdisciplinar mais completa que vá além das meras táticas militares.

As limitações epistemológicas de nossa pesquisa se deram pela escassez de fontes bibliográficas e a pouca abertura das instituições militares em se deixarem pesquisar. Essa temática educação militar vem ganhando espaço, apesar de tímido, nas lides acadêmicas e, necessário se faz que surjam mais pesquisadores dispostos a enveredar nessa linha de estudo, tanto do pensamento, quanto da história e da educação militar no Brasil, até porque, como demonstramos neste trabalho, o paradigma da pedagogia militar vem ganhando força e 
A pedagogia militar e a formação em direitos humanos nas missões de paz: uma interdisciplinaridade necessária

discursos favoráveis em vários estados brasileiros, onde as polícias militares vêm intervindo em escolas públicas de ensino, naquilo que podemos classificar como um novo fenômeno que é a "militarização" da educação básica brasileira.

À guisa de conclusão, temos que uma formação que privilegie a Educação em Direitos Humanos daria às missões de paz no exterior muito mais do que uma percepção de intervenção militar; mas uma conotação de missão militar humanística e restauradora, o que se traduz no lema basilar do Exército Brasileiro: "Exército, braço forte, mão amiga".

\section{REFERÊNCIAS}

ALTHUSSER, Louis. Aparelhos ideológicos de estado: nota sobre os aparelhos ideológicos de estado. 3. ed. Rio de Janeiro: Graal, 1985.

BOBBIO, Norberto. A era dos direitos. Rio de Janeiro: Campus, 1992.

BRASIL. Comissão Nacional da Verdade. Relatório. Brasília: CNV, 2014. Disponível em: <http://www.cnv.gov.br/images/pdf/relatorio/volume_1_ pagina_959_a_976.pdf>. Acesso em: 10 mar. 2017.

- Ministério da Defesa da República Federativa do Brasil. Portaria n. 1.069, de 5 de maio de 2011. Aprova o Manual de Emprego do Direito Internacional dos Conflitos Armados (DICA) nas Forças Armadas MD34-M-03. Brasília, DF, 2011a.

BRASIL. Lei n. 12.528, de 18 de novembro de 2011. Cria a Comissão Nacional da Verdade no âmbito da Casa Civil da Presidência da República. Brasília, DF, 2011b. Disponível em: <http://www.planalto.gov.br/ccivil_03/_ato20112014/2011/lei//12528.htm>. Acesso em: 9 nov. 2017.

. Portaria n. 156, de 23 de abril de 2002. Aprova o Vade-Mécum de Cerimonial Militar do Exército - Valores, Deveres e Ética Militares (VM 10). Brasília, DF. Disponível em: <http://www.sgex.eb.mil.br/index.php/ cerimonial/vade-mecum/106-valores-deveres-e-etica-militares>. Acesso em: 9 nov. 2017.

. Ministério da Educação. Parâmetros Curriculares Nacionais do Ensino Médio. Brasília: MEC, 2000. 
. Lei n. 9.394, de 20 de dezembro de 1996. Estabelece as diretrizes e bases da educação nacional. Brasília, DF. Disponível em: <http://www. planalto.gov.br/ccivil_03/leis/L9394.htm>. Acesso em: 1ㅇmar. 2017.

. Constituição da República Federativa do Brasil. Brasília: Congresso Nacional, 1988.

CASTRO, Castro. O espírito militar. 2. ed. Rio de Janeiro: Zahar, 2004.

COMPARATO, Fábio Konder. A afirmação histórica dos Direitos Humanos. 7. ed. São Paulo: Saraiva, 2010.

FAZENDA, Ivani. Interdisciplinaridade: história, teoria e pesquisa. 18. ed. Campinas, SP: Papirus, 2012.

FAZENDA, Ivani (Org.). Dicionário em construção: interdisciplinaridade. São Paulo: Cortez, 2002.

FOUCAULT, Michel. Microfísica do poder. 4. ed. Rio de Janeiro: Graal, 1984. GIRARDET, Raoul. A sociedade militar: de 1815 até nossos dias. Rio de Janeiro: Biblioteca do Exército, 2+000.

GUTIERREZ, José Paulo; URQUIZA, Antônio H. Aguilera (Org.). Direitos humanos e cidadania: desenvolvimento pela educação em direitos humanos. Campo Grande, MS: UFMS, 2013.

JAPIASSÚ, Hilton. Interdisciplinaridade e patologia do saber. Rio de Janeiro: Imago, 1976.

LUDWIG, Antônio Carlos Wil. A Democracia e ensino militar. São Paulo: Cortez, 1998.

LUCHETTI, Maria Salustre Rossi. O ensino no Exército brasileiro: história, quadro atual e reforma. Piracicaba, SP: UNIMEP, 2006.

NOGUEIRA, Jefferson Gomes. Educação militar: uma leitura da educação no Sistema dos Colégios Militares do Brasil (SCMB). 2014. Dissertação (Mestrado em Educação) - Universidade Federal de Mato Grosso do Sul (UFMS), Campo Grande, MS, 2014.

RODRIGUES, Fernando da Silva. Uma carreira: as formas de acesso à escola de formação de oficiais do Exército brasileiro no período de 1905 a 1946. 2008. Tese (Doutorado em História) - Universidade Federal do Rio de Janeiro (UFRJ), Rio de Janeiro, 2008.

WEBER, Max. Ensaios de sociologia. Rio de Janeiro. Editora Guanabara, 1982. 